\title{
A Escrita de Professores em Formação para a Educação Básica
}

\author{
Mariane de Barros Brum ${ }^{1}$ \\ Regina Caroline Bauer ${ }^{2}$ \\ Vandriane Tavares da Silveira ${ }^{2}$ \\ Felipe Gustsack ${ }^{3}$
}

\section{RESUMO}

Apresentamos, neste estudo, que resultou das ações do projeto de pesquisa Experiências de escrita e letramento na formação de professores para a Educação Básica, reflexões acerca de questões relacionadas à escrita de professores em formação. Nossa metodologia consistiu no levantamento e discussão de problemas de escrita a partir de 32 textos de alunos do Curso de Pedagogia - UNISC, com base nos critérios de coesão e coerência, ortografia e argumentação. Objetivamos questionar os efeitos decorrentes das dificuldades constatadas para a formação dos docentes, bem como as possíveis consequências para sua atuação profissional. Frente aos problemas encontrados, percebemos que a formação destes futuros alfabetizadores e mediadores de conhecimentos essenciais da escrita vem ocorrendo com carências que podem prejudicar a mediação da aprendizagem. Constatando que a insuficiência da prática de escrita contribui para tal realidade, pensamos que cabe ao ensino superior a tarefa de formular estratégias que modifiquem essa situação. Em suma, almejamos chamar atenção para esta realidade e salientar a necessidade de maiores percursos da experiência de escrita na formação de futuros formadores para a Educação Básica.

Palavras-chave: Escrita. Letramento. Professores. Formação. Educação Básica.

\begin{abstract}
We present in this study, that is part of the actions of the research project Writing and literacy experiences in teacher's training to Basic Education, reflections about questions related to the writing of teachers in training. Our methodology consisted of the collection and discussion of writing problems based on 32 texts of students of the Early Childhood and Elementary Education Course - UNISC. We aim to question the effects due the difficulties found to the teacher's training and the possible consequences for their professional performance. Facing the problems found, we realize that the training of these future literacy teachers and mediators of fundamental writing knowledge has been happening with poverties that can prejudice the mediation of learning. Realizing that this situation results from a lack of writing practice, we think that the higher education is responsible for creating strategies that try to change it. Summarizing, we intend to call attention to this reality and emphasize the importance of deepen writing experiences in the training of future teachers to Basic Education.
\end{abstract}

Keywords: Writing. Literacy. Teachers. Training. Basic Education.

\footnotetext{
${ }^{1}$ Aluna do Curso de Letras da Universidade de Santa Cruz do Sul - UNISC.

${ }^{2}$ Alunas do Curso de Pedagogia da Universidade de Santa Cruz do Sul.

${ }^{3}$ Professor do Departamento de Educação da Universidade de Santa Cruz do Sul. <fegus@unisc.br>
} 


\section{APRESENTAÇÃO}

As reflexões aqui apresentadas decorrem de um estudo integrado às ações de pesquisa do projeto Experiências de escrita e letramento na formação de professores para a Educação Básica, vinculado ao Programa de Pós Graduação em Educação da Universidade de Santa Cruz do Sul - UNISC e coordenado pelo professor Felipe Gustsack. Esta pesquisa emergiu da necessidade em refletirmos acerca da escrita de futuros professores dos anos iniciais da Educação Básica, devido às dificuldades constatadas na leitura de textos produzidos por acadêmicos $^{4}$ do curso de Licenciatura em Pedagogia da Universidade.

Nossas inquietações motivaram a realização de tal estudo ao considerarmos que os textos foram produzidos por futuros mediadores de experiências elementares no universo da escrita. Além disso, os aspectos em que foram identificadas dificuldades integram a aprendizagem dos anos iniciais.

Sendo assim, o que objetivamos é questionar e refletir a respeito dessa realidade, bem como sobre as possíveis consequências de tais carências para a formação dos docentes. Pensamos que esta situação precisa ser estudada para que possíveis soluções sejam encontradas. Não almejamos determiná-las neste estudo, todavia buscaremos apontar saídas para que tentativas efetivas possam ser realizadas. Ademais, objetivamos ressaltar e dar ênfase à importância de experiências de escrita para a formação de professores. Sendo assim, inicialmente discorremos a respeito das teorias que embasaram nossos questionamentos.

\section{FUNDAMENTAÇÃO TEÓRICA}

Nosso estudo, como mencionamos, se movimentou em torno de uma preocupação acerca da formação de futuros mediadores de conhecimentos da linguagem escrita. Ao iniciarmos nossas discussões, refletindo, primeiramente, a respeito da importância desses para a alfabetização, nos deparamos com teorias que evidenciavam a necessidade de o professor alfabetizador efetivamente conhecer a língua. Ao escrever sobre a alfabetização, José Morais (2014, p. 18-19) afirma que: "Uma habilidade só pode ser plenamente compreendida quando conhecemos as propriedades do material sobre o qual ela se exerce". No mesmo sentido, Tasca e Poersch (1990) defendem a ideia de que:

[...] a alfabetização lida com a linguagem e, consequentemente, exige do alfabetizador, além de conhecimentos didáticos, psicológicos e sociológicos, um

\footnotetext{
${ }^{4}$ Para efeitos deste artigo adotaremos a flexão de gênero no masculino.
} 
bom cabedal de conhecimentos acerca da linguagem. (TASCA e POERSCH, 1990, p. 13).

Por sua vez, Faraco (1992) aponta que:

o professor alfabetizador precisa, entre outras coisas, ter um bom conhecimento da organização do nosso sistema gráfico para poder melhor sistematizar seu ensino; para entender as dificuldades ortográficas de seus alunos e para auxiliá-los a superálas. (FARACO, 1992, p. 9).

A alfabetização se dá, principalmente, nos três primeiros anos do Ensino Fundamental, sendo que

em continuidade às experiências do letramento que vivenciaram na Educação Infantil e em seu ambiente familiar, nos anos iniciais do Ensino Fundamental ocorre a sistematização do processo de alfabetização, o que envolve processos sociais, políticos, econômicos e culturais. O conceito de alfabetização envolve tanto a apropriação do sistema alfabético e de aspectos da norma ortográfica, quanto o desenvolvimento de práticas de uso social da escrita (BRASIL, 2016, p.186).

Para Cagliari (2009, p.96), “um dos objetivos mais importantes da alfabetização é ensinar a escrever. A escrita é uma atividade nova para a criança, e por isso mesmo requer um tratamento especial na alfabetização. [...]”. Todavia, a escola não pode ensinar a escrever sem ensinar o que é escrever, ou seja, "é preciso ouvir das crianças o que é escrever, para que serve a escrita, valorizando as opiniões que cada uma possa apresentar" (CAGLIARI, 2009, p.99). Vale ressaltar que algumas pesquisas mostram que a criança...

[...] experimenta escrever textos e palavras mesmo antes de um ensino sistemático. Assim, é importante que o/a professor/a permita que as crianças escrevam de forma não convencional (da maneira como acham que podem escrever, de forma mais espontânea) pois, conhecendo sua forma de pensar a escrita, pode trabalhar em direção ao domínio progressivo da escrita e da leitura (BRASIL, 2016, p. 187).

Mas, para isso, o professor precisa saber utilizar a forma mais adequada (ou correta) da escrita, mediando a relação das crianças com o processo de escrever. Dessa maneira, podemos assumir que se caracteriza como fundamental que ele conheça a estrutura e o funcionamento da língua, como afirmam Tasca e Poersch (1990). Além de ser responsável pela alfabetização, ele também auxiliará o aluno na aprendizagem da ortografia e de princípios básicos da produção textual. Esses conhecimentos precisam se constituir como uma base sólida para que 
o aluno os desenvolva (e se desenvolva) da melhor forma possível nas demais etapas escolares. Sendo assim, esse mediador dos conhecimentos essenciais da escrita, precisa saber, para que auxilie seu aluno, produzir textos coerentes a diferentes contextos, já que o objetivo do ensino da língua portuguesa é o de "[...] ampliar as competências comunicativointeracionais dos alunos" (ANTUNES, 2003, p. 34). Tal proposta embasa diversas teorias e propostas de estudo, constando na segunda versão da Base Nacional Comum Curricular (2016, p. 87), que postula que o ensino da língua portuguesa na Educação Básica precisa: “[...] proporcionar aos/às estudantes experiências que ampliem suas ações de linguagem, contribuindo para o desenvolvimento do letramento, entendido como uma condição que permite ler e escrever em diversas situações pessoais, sociais e escolares”.

E, por conta disso, o conhecimento da variação linguística considerada padrão em nossa sociedade também é de suma importância. Com isso, não queremos afirmar que os acadêmicos envolvidos nessa pesquisa, por exemplo, necessitem decorar compêndios de gramática normativa ou algo do gênero. Todavia, o que ressaltamos, com base em teóricos como os já mencionados, é que eles demonstrem conhecer sua língua, o que inclui suas variações, para que saibam como melhor auxiliar seus futuros alunos a ter experiências nela, a estudá-la, e, assim, aprender, expandindo suas possibilidades de comunicação.

Tal responsabilidade requer, portanto, que o docente também possua uma boa prática de escrita, que tenha experiências nela, para que desenvolva conhecimentos sobre ela. Muitos teóricos como Cagliari (2009), Faraco (1992) e Tasca e Poersch (1990) apontam para a necessidade de o professor alfabetizador e mediador de conhecimentos da linguagem escrita possuir conhecimentos linguísticos, como fonéticos, sintáticos e textuais, aprofundados. Não nos cabe aqui discutir a respeito, porém concordamos com o fato de que eles auxiliam na mediação da aprendizagem, visto que explicam o funcionamento da língua.

No entanto, aprofundar saberes é algo que depende de como o docente se relaciona com o conhecimento que media. Masschelein e Simons (2013, p. 76), discorrendo a respeito do amor que "entra em cena no fazer a escola", que se configura como o "amor pelo assunto, pela causa (ou pelo mundo) e amor pelos alunos" (MASSCHELEIN; SIMONS, 2013, p. 76, grifos nossos), esclarecem que "fazer a escola reside, em parte, no amateurismo do professor.” (MASSCHELEIN; SIMONS, 2013, p. 77). Para os autores,

Um professor é alguém que ama seu tema ou matéria, que se preocupa com ela e presta atenção a ela. [...] Não só é conhecedor de matemática, mas apaixonado pelo assunto, inspirado por seu trabalho e pelo material. Esse é um entusiasmo que se mostra nas pequenas ações ou gestos precisos, expressões de seu conhecimento, mas 
também expressões de sua preocupação com o trabalho à mão e seu lugar nele. [...] Várias coisas convergem no amor pelo assunto: respeito, atenção, dedicação, paixão. $\mathrm{O}$ amor se mostra numa espécie de respeito e atenção pela 'natureza da matéria' ou pelo material com que o professor está comprometido. (MASSCHELEIN; SIMONS, 2013, p. 77).

Do mesmo modo, os autores pontuam que o professor amateur pode ser reconhecido por sua busca pela perfeição, o que não se refere a uma atitude patológica, mas sim que "[...] é o perfeccionismo do professor de inglês que exige respeito e atenção à língua. As coisas têm de ser corretas. Não só prepara sua aula, mas também a si mesmo." (MASSCHELEIN; SIMONS, 2013, p. 79).

A partir disso, pensamos que a relação do professor com a escrita se configura como um dos pontos cruciais não somente em termos de aprofundamento de conhecimentos, mas principalmente porque tal relacionamento influi diretamente em sua didática. Isto é, o modo como o professor concebe e se relaciona com a escrita (com a língua) reflete na forma como ele irá apresentá-la aos alunos, auxiliá-los a estudá-la e nas experiências que proporcionará. Se ele revela conhecer a linguagem escrita de forma aprofundada, demonstrando, portanto, respeito, atenção, dedicação e paixão por ela, além da mediação dos conhecimentos poder ocorrer de melhor forma, a possibilidade de os estudantes também a conceberam no mesmo sentido e despertarem interesse em estudá-la poderá ser mais efetiva.

Não obstante, disso também decorre uma concepção de aprendizagem e estudo da linguagem escrita não somente com objetivos específicos, como, por exemplo, a etapa necessária de um processo para atingirmos um fim, tal como a formação acadêmica, mas de compreendê-la em toda sua abrangência, o que implica conhecer sua história, sua natureza. Sendo o papel do professor tão valioso, seria de se esperar que fosse de seu conhecimento a origem e a evolução da escrita, bem como o reconhecimento de seu valor para a humanidade. Apesar disso, Cagliari postula ser “[...] comum os professores de português ou de alfabetização saberem muito pouco sobre a natureza da escrita, como funciona, como deve ser usada em diferentes situações”. (CAGLIARI, 2009, p. 82).

Seu surgimento, há cerca de dez mil anos, conforme Horcades (2004) ocorreu devido à necessidade do homem em organizar a sociedade e possibilitou o acúmulo do conhecimento humano. Segundo Cagliari (2009), somente após longa evolução que se deu o aparecimento do sistema de escrita alfabética. A partir desse é que essa forma de comunicação se constituiu como a mais importante, segundo abordagem de Echeverría (2006).

A importância atribuída à escrita já era evidenciada na Grécia Antiga. Segundo Morais (2014, p. 24), “em Atenas, a escrita era considerada uma marca de cultura. [...] afirmava-se 
que a criança que recebia uma boa educação se tornaria um cidadão útil à cidade". Seu valor também se faz evidente quando refletimos ser um dos fatores que possibilita o estabelecimento do poder, como aborda Gnerre (1998), além de estar diretamente relacionada à posição social. Conforme o autor, a linguagem do falante comunica ao ouvinte o lugar que ele ocupa (ou pensa ocupar) na sociedade, por isso a importância dos indivíduos ampliarem suas possibilidades de comunicação. Neste sentido, o autor pontua que a linguagem é uma forma de ascensão social. Além disso, segundo Gnerre (1998, p. 21), ela "pode ser usada para impedir a comunicação de informações para grandes setores da população".

O desconhecimento de fatos que caracterizam a importância da escrita para a constituição do indivíduo e a vida em sociedade pode fazer com que aquela não seja valorizada enquanto algo revolucionário, libertador e transformador, possibilitadora da comunicação e potencializadora de experiências. Em decorrência disso, sua prática pode se configurar como não tão frequente, e a necessidade de ampliar suas ações de linguagem, ou seja, em estudar e se dedicar à língua para a comunicação em diferentes situações e contextos, ser desvalorizada. No que tange à formação de futuros professores, consideramos que tal concepção pode influenciar na aprendizagem do então acadêmico enquanto futuro professor, visto que, por não concebê-la de tal maneira, possivelmente não se empenhará em estudá-la com atenção e dedicação (com amor pelo assunto). Não obstante, também pode prejudicar no ensino deste futuro professor que provavelmente não apresentará o universo da escrita ao aluno de forma que o convide a compreendê-lo como algo (trans)formador, dificultando a mobilização de seu interesse, como mencionamos anteriormente.

Em suma, como mediador dos conhecimentos da escrita, o professor necessita possuir uma formação que lhe possibilite auxiliar os alunos em seu percurso de aprendizagem. Dessa forma, é necessário que conheça seus aspectos essenciais (sua estrutura e seu funcionamento) e, mais do que isso, sua história, reconhecendo seu valor, para que possa proporcionar tal entendimento ao aluno, o que pode gerar sua atenção e dedicação ao estudo da linguagem.

Todavia, ao estudarmos os textos de alunos de Pedagogia/UNISC, o que encontramos não atestou um conhecimento sólido sobre a escrita, instigando reflexões como as já expostas.

\section{PRODUÇÃO E TRATAMENTO DOS DADOS}

A produção da amostra de textos foi realizada com uma turma de 32 acadêmicos do Curso de Pedagogia da Universidade de Santa Cruz do Sul no segundo semestre de 2015. Essa experiência de escrita foi realizada como atividade pedagógica para a disciplina de 
Seminário de Pesquisa em Educação I, envolvendo alunos que se encontravam, na sua maioria, no quarto semestre do respectivo curso. Essa disciplina tem por objeto principal a elaboração, pelos acadêmicos, de projetos de pesquisa. Assim, o objetivo didático foi o de um exercício para a aprendizagem da escrita acadêmica/científica, porém foi realizado acordo de pesquisa com os estudantes no sentido de sua ciência quanto ao uso de seus textos como material de nossa pesquisa sobre a escrita.

Como metodologia para o tratamento dos dados, realizamos um levantamento seguido de discussões acerca de dificuldades percebidas em sua escrita, com foco nos aspectos de produção textual, envolvendo, portanto, fatores ortográficos e gramaticais. Os critérios que orientaram nossa pesquisa foram os de coesão e coerência, ortografia e argumentação. No primeiro estudamos a sequenciação, a referenciação e questões como o domínio de vocabulário, além de outros aspectos da superfície textual como a sintaxe de concordância. No segundo, consideramos a pontuação, a acentuação e a grafia das palavras. E no último critério baseamo-nos no desenvolvimento, na consistência e na eficácia da argumentação dos autores. Os aspectos mencionados foram estudados com base em trabalhos de Bechara (2009), Cegalla (2010) e Koch (1990, 2006), que fundamentaram nossos levantamentos e reflexões.

Neste trabalho, utilizamos tanto da metodologia qualitativa quanto quantitativa, pois além de refletirmos a respeito dos dados encontrados também os quantificamos, aprofundando a compreensão a respeito da escrita dos estudantes. Para Fonseca (2002, p. 20), "diferentemente da pesquisa qualitativa, os resultados da pesquisa quantitativa podem ser quantificados [...]", o que possibilita levantamento, nomeação e enumeração de categorias de análise. A utilização destas formas de pesquisa nos "permite recolher mais informações do que se poderia conseguir isoladamente" (FONSECA, 2002, p.20).

Discutimos, anteriormente, a respeito das teorias que deram suporte aos nossos estudos e ressaltamos a importância de saberes aprofundados para o ensino da escrita. Todavia, os resultados que obtivemos revelam a carência desses entre os participantes da pesquisa.

Nossa exposição se organiza conforme os critérios que nortearam a pesquisa, apresentados acima. Começamos, então, por discorrer a respeito da coesão e coerência textuais. Nesse quesito, por volta de $75 \%$ das produções apresentaram dificuldade, em aspectos que variaram de uns para outros. Inicialmente, apontamos para o fato de que todas as produções são coerentes. Entendemos o conceito de coerência conforme Koch e Travaglia (1990, p. 21), enquanto “[...] o que faz com que o texto faça sentido para os usuários. [...] Este sentido, evidentemente, deve ser do todo, pois a coerência é global.” Segundo os autores, “[...] 
para haver coerência é preciso que haja possibilidade de estabelecer no texto alguma forma de unidade ou relação entre seus elementos" (KOCH; TRAVAGLIA, 1990, p. 21-22).

Com base nisso, afirmamos que as produções dos alunos possuem coerência, pois conseguimos extrair um sentido de seu todo. Outro fato que contribuiu para tal conclusão foi que conseguimos perceber, em todos os textos, uma continuidade de ideias - mesmo com dificuldades em seu desenvolvimento. Por conta desse problema em estruturá-las, em alguns momentos percebíamos uma mudança um tanto quanto abrupta de segmentos tópicos. Aqui compreendemos que "um texto [...] compõe-se de segmentos tópicos, direta ou indiretamente relacionados com o tema geral ou tópico discursivo" (KOCH; ELIAS, 2006, p. 179). Apesar disso, compreendemos que não havia rupturas semânticas entre os segmentos, mas que as inadequações em seu encadeamento e segmentação muitas vezes causavam certa dificuldade na concatenação das ideias. Todavia, sempre era possível apreender a continuidade entre elas.

No entanto, apesar de compreendermos a ideia dos autores, suas intenções, e, portanto, conseguirmos atribuir um sentido ao todo da produção, identificamos diversos tipos de incoerências locais nos textos. Citando Van Dijk e Kintsch (1983), Koch e Travaglia (1990, p. 41) esclarecem que os autores "[...] falam de coerência local, referente a parte do texto ou a frases ou a sequências de frases dentro do texto [...]". Para eles, o mau uso dos elementos linguísticos em sequências menores gera, portanto, incoerências locais.

É importante ressaltar que Koch e Travaglia (1990, p. 42) pontuam que "a incoerência local não impede totalmente o cálculo do sentido, embora o torne mais difícil", o que fundamenta nossas asserções quanto a considerarmos os textos dos alunos coerentes, mesmo com as incoerências locais encontradas. Um dos aspectos que chamou atenção pelo número de casos encontrados (31\%) foi a falta de domínio de vocabulário. Ou seja, observamos ocorrências de escolhas equivocadas de palavras, em que necessitávamos inferir o que o autor almejava expressar, fato que demonstrava uma incoerência semântica.

Outro ponto que se destacou foram os casos de incoerência sintática, como no trecho: "A partir dos anos 80 e 90, os enfoques se multiplicam e se diversificam, dando espaço a abordagens críticas, onde que se passa compreender e interpretar grande parte das questões (...)”. Aqui o mais adequado seria a utilização da conjunção "quando".

No aspecto da coesão também encontramos dificuldades na grande maioria das produções. O critério foi estudado com base nos postulados de Koch e Travaglia (1990, p. 47), que afirmam ser a coesão "a ligação, a relação, os nexos que se estabelecem entre os elementos que constituem a superfície textual. [...], explicitamente revelada através de marcas 
linguísticas, índices formais na estrutura da sequência linguística e superficial do texto" (KOCH; TRAVAGLIA, 1990, p. 47).

Segundo os autores, a coesão possui duas grandes modalidades: remissiva ou referencial (remissão ou referenciação) e sequencial (ou sequenciação). Por coesão referencial entendemos, conforme Koch e Travaglia (1990, p. 47), ser a ligação "que se estabelece entre dois ou mais componentes da superfície textual que remetem a (ou permitem recuperar) um mesmo referente". De acordo com os autores, ela é obtida por meio da substituição e da reiteração. Neste sentido, observamos a falta do uso de sinônimos, pois percebemos o uso repetitivo de alguns termos em parte das produções textuais. Também constatamos inadequações quanto à coesão referencial por substituição, nos casos em que a retomada do sujeito era feita sem que o elemento gramatical concordasse com ele, como no trecho: "estas, são muito importante, porque ela aborda as questões dos julgamentos, práticas”.

A coesão sequencial se revelou como um dos aspectos mais problemáticos na escrita dos estudantes. Compreendemos o conceito segundo Koch e Travaglia (1990), que estabelecem que ela ocorre por meio dos procedimentos de recorrência e progressão. $\mathrm{O}$ que mais nos interessa nesse estudo é o segundo mecanismo, aspecto em que mais identificamos dificuldade no que diz respeito à coesão. De acordo com os autores, a progressão é realizada através de mecanismos como o uso de termos de um mesmo campo lexical, bem como de conectores e operadores discursivos que possibilitam os encadeamentos, um dos importantes fatores que proporciona a sequenciação do texto. Nas produções textuais dos futuros professores, percebemos, em sua grande maioria, como já exposto, dificuldade na sequenciação do texto, especialmente no que diz respeito ao encadeamento.

Em um texto, por exemplo, o autor somente adicionava informações com as conjunções aditivas "também" e "e", não estabelecendo conexões e relações adequadas entre os enunciados e parágrafos, sendo tal realidade identificada em grande parte das produções. No mesmo sentido, em sua maioria constatamos a ausência de alguns conectivos, os quais necessitávamos inferir pelo contexto para produzir o sentido completo do enunciado, o que prejudicava na coesão sequencial, e, portanto, no estabelecimento do sentido.

Não obstante, percebemos, ainda nesse quesito, que os autores possuíam dificuldade quanto à segmentação. Na maioria dos textos constatamos que a inadequada segregação dos termos em enunciados ou desses em parágrafos complicava o estabelecimento do sentido, como evidencia o seguinte trecho: "O texto [...] relata questões discutidas em busca de aperfeiçoar a pesquisa em educação, um grupo de trabalho composto por seis pesquisadores fez pesquisas para relatar quais os métodos para a realização de uma boa pesquisa e 
concluíram que para ter qualidade na pesquisa, é preciso promover debates em diferentes ambos sociais, para assim ter concepções consensais de uma 'boa' ou 'má ' pesquisa".

Ademais, identificamos uma série de outros problemas na escrita dos acadêmicos. Na grande maioria dos textos havia construções mal elaboradas e com inadequações gramaticais, que prejudicavam a construção do sentido. Em diversos casos constatamos a falta de elementos gramaticais (em geral preposições) ou a inadequada presença deles. A seguir elencamos alguns exemplos das inadequações identificadas: "sabe-las usar (...)”; "A pesquisa em educação apresentada no texto de Marli André que há uma longa história de pesquisa mas precisa rever e analisar o que se vem buscando para se aprimorar"; "É neste periódo que os estudos chamados de qualitativos, que englobam um conjunto de métodos e técnicas e análises discursso de narrativas hitória de vida".

No mesmo sentido, cerca de $28 \%$ dos textos demonstraram inadequações na sintaxe de concordância nominal e $78 \%$ de concordância verbal. Na concordância entre os nomes constatamos principalmente casos de inadequação de número. No que diz respeito à concordância verbal, observamos diversos casos de falta de concordância entre o verbo e seu sujeito, e, principalmente, casos de inadequada flexão dos verbos "ter" e "vir" na $3^{\text {a }}$ pessoa do plural, que apareceram na grande maioria das produções. Destacamos alguns exemplos: "diversificando em variáveis contexto"; "foi criado uma variedade de temas que levou os pesquisadores procurarem autores e conceitos para poder"; "Estas propos de pesquisas é ". Salientamos que tais inadequações não impossibilitam a extração de um sentido para o texto, mas fazem com que tenhamos que nos esforçar para cooperar em seu estabelecimento.

O segundo critério estudado foi o de ortografia, em que discutimos a respeito da grafia, acentuação e pontuação das palavras. Nesse último aspecto, encontramos, em cerca de $71 \%$ dos textos, uma utilização que prejudicava a extração do sentido. Identificamos inadequações em relação a critérios básicos da pontuação, como o emprego da vírgula entre o sujeito e o verbo da oração, ou entre o verbo e seus complementos, além da falta de vírgula entre expressões explicativas e/ou retificativas (cf. CEGALLA, 2010, p. 429-430). Alguns trechos evidenciam tal realidade: "estas, são muito importante"; "No meu projeto de pesquisa de será o tema: sobre autista, relaciona com texto, que devemos ser claros e objetivos"; "Em fim, sempre é bom ler textos, autores que venham contribuir, em minha aprendizagem”.

No que tange à acentuação, em $78 \%$ dos textos constatamos alguma inadequação, tais como: "docênte", "saude", "pedagogico", "academico", "ciêntificos"; "está" (ao invés de "esta"); "necessario", "responsaveis", "referêncial", "ultimos", "explicita" (ao invés de “explícita”), "falavamos", “critica” (ao invés de “crítica”), etc. 
Ademais, 46\% demonstrou dificuldade na grafia das palavras, como nos casos: "basease”, “pesquiza”, “em fim”, “seção” (ao invés de "sessão”), “apartir”, “achavasse”, “analizar”, “trás" (ao invés de "traz"), "entorno", "ouve” ao invés de "houve”, e etc.

Outro aspecto percebido foi a falta de revisão, constatada, por exemplo, nas construções com palavras suprimidas e nos casos em que os autores iniciavam um novo enunciado em uma voz verbal e logo após a modificavam sem alterar o começo da construção para que fosse promovida a devida concordância entre os elementos.

Todavia, ressaltamos que há aspectos positivos nas produções, como é o caso do terceiro critério: a argumentação. Constatamos que os autores em geral possuem habilidade quanto ao caráter argumentativo, fundamentando seus argumentos em teorias e utilizando estratégias como criações de exemplos para a defesa de suas teses.

\section{IMPACTOS PARA A FORMAÇÃO DOCENTE}

Discutimos a importância de que o professor, para exercer com qualidade sua função, precisa ter conhecimentos profundos e sólidos a respeito do que ensina - nesse caso, a linguagem escrita. Entretanto, os resultados apresentados tornam evidente a falta de correspondência a tais postulados. Assim, então, voltamos à questão que norteou nossa pesquisa: Quais são as consequências, decorrentes das dificuldades constatadas, para a formação destes docentes?

Primeiramente, ressaltamos que não pretendemos afirmar com este estudo que os professores necessitem decorar regras da norma gramatical para atuarem em sala de aula. Todavia, o que propomos é que possuam o conhecimento e entendimento necessários sobre a escrita para que possam proporcionar um melhor auxílio ao aluno, elaborando propostas de estudo, identificando as dificuldades dos estudantes e ajudando-os a enfrentá-las.

Como pontuamos na fundamentação teórica, o futuro professor, introdutor de saberes essenciais da escrita, precisa conhecer a estrutura e o funcionamento da língua para que possa auxiliar o aluno a se comunicar de forma adequada nas mais variadas situações. Porém, se ele próprio desconhece, por exemplo, a forma ortográfica de palavras amplamente utilizadas, apresenta dificuldades na pontuação e na elaboração de textos, como constatamos, o auxílio ao aluno poderá se tornar mais frágil. Em outras palavras, as dificuldades encontradas podem prejudicar na mediação da aprendizagem, visto que podem vir a ser reproduzidas na sala de aula pelos próprios professores e, então, até por seus alunos. Conforme Cagliari (2009): 
O professor de português tem que ser um profissional competente, tem que conhecer profundamente a língua portuguesa. Como pode ele ensinar o que não sabe? Se ele tiver um conhecimento errado, seu trabalho vai ser ensinado errado!... (CAGLIARI, 2009, p. 36).

As dificuldades encontradas nos textos, como as incoerências locais e os problemas de coesão - principalmente de sequenciação -, chamam nossa atenção para possíveis consequências negativas na prática desses futuros professores. Neste último caso, ressaltamos, citando Tasca e Poersch (1990), o quão relevantes são os conhecimentos a nível textual, especialmente no que tange ao domínio do significado das conjunções e locuções conjuntivas, que encadeiam as partes do discurso, domínio que não foi constatado em grande parte da produção dos acadêmicos. Como nos anos iniciais as crianças iniciam a prática de produções escritas, tais inadequações poderão implicar tanto na mediação dos conhecimentos em si, quanto na elaboração de propostas de atividades de aprendizagem ou de estratégias para o desenvolvimento da textualização (GUSTSACK, 2013).

Nesse período, os alunos também aprendem as noções elementares da ortografia, o que faz com que os problemas encontrados em tal categoria se configurem como prejudiciais para sua aprendizagem. É fundamental que o professor possua conhecimentos sólidos sobre nosso sistema ortográfico, o que inclui a grafia das palavras conforme estabelecida pela norma gramatical, bem como o porquê de seu estabelecimento, suas implicações e variações. Afinal, conforme Morais (1999, p. 11), a ortografia foi criada no intuito de manter "[...] um casamento entre o ideal fonográfico (uma escrita que refletisse regularmente uma forma idealizada de pronunciar) e o princípio ideográfico (que opta por manter a etimologia, a notação das palavras em sua língua original)".

Atentando para este fato, pontuamos que Tasca e Poersch (1990, p. 23), ao discorrerem a respeito da importância do professor ter consciência da origem das distorções na relação fonema/grafema, afirmam que “[...] a única explicação para o fato de escrevermos os três homófonos (sessão, cessão, seção) de formas diferentes, ou de conservarmos o $h$ em hora, apesar de ser pronunciado ora, é a etimologia". Todavia, como apresentamos anteriormente, os acadêmicos demonstraram dificuldade na escrita de palavras demasiado semelhantes: "seção" ao invés de "sessão", como podíamos inferir pelo contexto, e "ouve" ao invés de "houve". Conforme postula, em seguida, este mesmo autor, "ao professor [...] convém ter consciência desta realidade para poder prever dificuldades, descobrir as causas dos desvios [...]" (TASCA e POERSCH, 1990, p. 24). Não obstante, ao abordar sobre o caráter gerativo da ortografia, Rego e Buarque (1999) colocam que boa parte dos desafios do processo de 
ensino-aprendizagem desta consiste na criação de situações didáticas que possibilitem ao aluno compreender as restrições contextuais da língua. Mas a falta de conhecimentos dela e sobre ela, no entanto, dificulta a realização desses postulados.

Os problemas de concordância, de acentuação e pontuação também indicam a possibilidade de a mediação de conhecimentos e o auxílio ao aluno serem prejudicados. Neste último quesito, chamamos atenção para a importância do estudo da pontuação para os anos iniciais. Conforme Silva e Brandão (1999, p. 122), a "pontuação [...] tem um papel essencial na leitura e na produção de textos, algo que deve constituir um dos principais eixos do trabalho nas séries iniciais". Não obstante, ressaltam que cabe ao professor criar situações didáticas para que o aluno descubra o funcionamento dos sinais gráficos. Porém, tal estratégia inviabiliza-se quando o próprio professor possui problemas na sua utilização.

Esta realidade preocupa muitos teóricos, pois interfere diretamente na mediação da aprendizagem. Como pontua Morais (2014, p. 35): "Vários estudos têm mostrado que muitos professores não sabem o suficiente sobre o modo como a criança aprende a ler e como se deve ensiná-la, nem têm conhecimento explícito aprofundado da língua e do código ortográfico".

Além disso, não só essas carências, mas a própria falta de experiências de escrita podem vir a configurar uma espécie de "círculo vicioso". Aqui, enfatizamos o que expomos anteriormente a respeito da importância de como o professor se relaciona com a escrita. $\mathrm{O}$ fato de esses futuros professores demonstrarem não possuir uma boa prática de escrita, conforme podemos constatar com os resultados obtidos, poderá refletir em sua atuação e influenciar no processo de aprendizagem das crianças.

Voltamos a salientar que não almejamos, com tais constatações, afirmar que o professor não possa cometer inadequações, mas sim, que se faz necessário que ele possua conhecimentos sobre o funcionamento da linguagem escrita, para que possa auxiliar o aluno a desenvolver sua competência comunicativa. É fundamental que entenda, para auxiliar o aluno a compreender o mesmo, que a linguagem escrita necessita de estudo e de prática para que consigamos, com ela, nos expressar e sermos compreendidos.

\section{CONSIDERAÇÕES FINAIS}

Como afirmamos no início deste artigo, não objetivamos apresentar alternativas para confrontar os resultados obtidos. Entretanto, sugerimos que modificações no currículo que aprofundem a experiência de escrita no período inicial do curso podem auxiliar no enfrentamento de tais dificuldades. 
Estamos cientes de que há estratégias como programas de extensão e atividades extraclasse. Porém, como relatado por Gustsack (2013), quando realizou oficinas com o intuito de promover experiências de escrita, a frequência é muito abaixo do esperado.

Sabemos que a proposta de aprofundar os conhecimentos e as experiências de escrita é uma tarefa difícil. Todavia, argumentamos, que, se o aluno/futuro professor apresenta dificuldades ao ingressar na universidade, estas não podem ser continuadas no ensino superior sem ao menos tentativas efetivas de resolvê-las.

O aprofundamento da prática da escrita, associada a uma intensificação da atividade de leitura, possivelmente contribuirão para que o quadro apresentado anteriormente melhore, bem como para que os futuros professores desenvolvam experiências de escrita e, assim, qualifiquem sua prática de modo a propiciarem aos alunos o auxílio de que necessitam.

Como este se apresenta como um estudo inicial, nossas conclusões são parciais. Constatamos que as dificuldades encontradas nas produções textuais dos professores em formação podem ter consequências significativas para a sua prática em sala de aula, havendo a possibilidade de prejudicar na mediação da aprendizagem dos alunos.

Ressaltamos a importância do enfrentamento dessas carências na universidade, no intuito de que haja tentativas efetivas de solucionar os problemas de escrita, aprofundando seus conhecimentos e sua prática. Além disso, salientamos a importância de conscientizar os futuros professores a respeito da necessidade de possuírem uma boa escrita como essencial para a sua prática docente enquanto alfabetizador e mediador dos conhecimentos dos anos iniciais. Enquanto isso não for percebido, o valor da linguagem escrita pode continuar não sendo reconhecido e a falta de prática e experiências permanecer.

Deixamos muitas questões a serem exploradas, como a origem dessas dificuldades na aprendizagem da escrita e os fatores que a influenciam, aspectos que podem ser desenvolvidos em estudos futuros no intuito de uma maior contribuição em debates para a qualificação da formação de professores. Em suma, este estudo almeja chamar atenção e salientar a importância da experiência de escrita na formação de futuros formadores para qualificar a aprendizagem da escrita na Educação Básica.

\section{REFERÊNCIAS}

ANTUNES, I. Aula de português: encontro \& interação. 1. ed. São Paulo: Parábola, 2003.

BECHARA, E. Moderna Gramática Portuguesa. 37. ed. Rio de Janeiro: Nova Fronteira, 2009. 
BRASIL. Base Nacional Comum Curricular. 2 ${ }^{\text {a }}$ Versão Revista. Brasilia/DF: MEC, 2016. Disponível em: <http://movimentopelabase.org.br/wp-content/uploads/2016/05/BNCCBOOK-WEB.pdf>. Acesso em: 10 fev. 2017.

CAGLIARI, L. C. Alfabetização \& linguística. 1. ed. São Paulo: Scipione, 2009.

CEGALLA, D. P. Novíssima gramática da língua portuguesa. 48. ed., rev. São Paulo: Ed. Nacional, 2010.

ECHEVERRÍA, R. Ontología del lenguaje. 1. ed. Buenos Aires: Granica: Juan Carlos Saez, 2006.

FARACO, C. A. Escrita e alfabetização: características do sistema gráfico do português. 1. ed. São Paulo: Contexto, 1992.

FONSECA, J. J. S. da. Metodologia da pesquisa científica. Fortaleza: UEC, 2002. Apostila.

GNERRE, M. Linguagem, escrita e poder. 1.ed. São Paulo: Martins Fontes, 1998.

GUSTSACK, F. Problematizando a escrita com professoras em formação. Revista Conjectura: Filosofia e Educação, Caxias do Sul, v. 18, n. 3, p. 107-123, 2013. Disponível em: $<$ http://www.ucs.br/etc/revistas/index.php/conjectura/article/view/2102/pdf_175>. Acesso em: 10 fev. 2017.

HORCADES, C. M. Evolução da escrita: história ilustrada. Rio de Janeiro: Senac Rio, 2004.

KOCH, I. G. V.; TRAVAGLIA, L. C. A coerência textual. 1. ed. São Paulo: Contexto, 1990.

KOCH, I. G. V.; ELIAS, V. M. Ler e compreender: os sentidos do texto. 1. ed. São Paulo: Contexto, 2006.

MASSCHELEIN, J.; SIMONS, M. Em defesa da escola: uma questão pública. 1. ed. Belo Horizonte: Autêntica, 2013.

MORAIS, A. G. de. Ortografia: este peculiar objeto. In: $O$ aprendizado da ortografia. 1. ed. Belo Horizonte: Autêntica, 1999.

MORAIS, J. Alfabetizar para a democracia. 1. ed. Porto Alegre: Penso, 2014.

REGO, L. L. B.; BUARQUE, L. L. Algumas fontes de dificuldade na aprendizagem de regras ortográficas. In: MORAIS, A. G. (Org.). O aprendizado da ortografia. 1. ed. Belo Horizonte: Autêntica, 1999.

SILVA, C. S.; BRANDÃO, A. C. P. Reflexões sobre o ensino e a aprendizagem da pontuação. In: MORAIS, A. G. (Org.). O aprendizado da ortografia. 1. ed. Belo Horizonte: Autêntica, 1999.

TASCA, M.; POERSCH, J. M. (Coord.). Suportes linguísticos para a alfabetização. 2. ed. Porto Alegre: Sagra, 1990. 
Como citar este documento: BRUM, Mariane de Barros et al. A Escrita de Professores em Formação para a Educação Básica. Revista Jovens Pesquisadores, Santa Cruz do Sul, v. 7, n. 1, jan. 2017. ISSN 2237-048X. Disponível em: <https://online.unisc.br/seer/index.php/jovenspesquisadores/article/view/9309>. Acesso em: ... doi: http://dx.doi.org/10.17058/rjp.v7i1.9309. 